\title{
SISTEMA AUTOMÁTICO PARA O CONTROLE EFICIENTE DE ILUMINAÇÃO PARA MULTIPLAS LÂMPADAS FLUORESCENTES
}

\author{
Moacyr A. G. de Brito* \\ moa.brito@gmail.com
}

Leonardo P. Sampaio*

\author{
Castellane S. Ferreira*
}

\author{
Carlos A. Canesin* \\ canesin@dee.feis.unesp.br
}

\author{
*Universidade Estadual Paulista - UNESP \\ Laboratório de Eletrônica de Potência - Departamento de Engenharia Elétrica \\ Ilha Solteira,São Paulo, Brasil
}

\begin{abstract}
Automatic System for the Efficient Control of Illumination for Multiple Fluorescent Lamps

This paper presents the development and implementation of an automatic multi-lamp lighting fluorescent system, with digital average current mode control for input power factor correction, based on electronic ballasts with capacity of ideal programmable preheating and dimming capabilities. Furthermore, the proposed system allows remote monitoring and management through a friendly software platform, where the system operates automatically or manually, according to the needs of each environment and/or user, optimizing the comsumption of electrical energy.
\end{abstract}

KEYWORDS: Dimming Control, Digital Control, Active Power Factor Correction, Fluorescent Illumination and Smart Grid Control for Illumination.

\section{RESUMO}

Este artigo apresenta o desenvolvimento e a implementação de um sistema de iluminação automático multi-lâmpadas fluorescentes, com correção ativa do fator de potência de entrada utilizando a técnica dos valores médios instantâneos

Artigo submetido em 17/01/2011 (Id.: 1251)

Revisado em 16/03/2011, 20/06/2011, 30/09/2011

Aceito sob recomendação do Editor Associado Prof. Francisco de Assis dos Santos Neves na forma digital, com capacidade de pré-aquecimento programável dos filamentos dos eletrodos e com controle de luminosidade. Além disso, o sistema proposto permite o gerenciamento e supervisão remota através de uma plataforma computacional amigável ao usuário, onde o sistema opera de forma automática ou manual, de acordo com a necessidade de cada ambiente e/ou do usuário, otimizando o consumo de energia elétrica.

PALAVRAS-CHAVE: Controle de Luminosidade, Controle Digital, Correção Ativa do Fator de Potência, Iluminação Fluorescente e Rede Inteligente para o Controle de Iluminação.

\section{INTRODUÇÃO}

A iluminação artificial é responsável por grande parcela de consumo de energia elétrica no país, totalizando $17 \%$ de toda energia consumida, representando $24 \%$ do consumo no setor residencial e por mais de $44 \%$ do consumo no setor de comércio e serviços (MME, 2007). Assim, verifica-se que é essencial e viável projetar sistemas de iluminação extremamente eficientes e adequados a cada ambiente, a fim de reduzir o impacto energético que estes sistemas apresentam.

Estes sistemas apresentam altos custos de implantação nos dias atuais. Entretanto, os custos com o aperfeiçoamento no sistema de iluminação podem ser amortizados com o aumento da produtividade, como já comprovado em estudos 
realizados no edifício comercial Lockheed-Martin's Building 157 em Sunnyvale, Califórnia. No caso em questão, os custos para se ter este sistema de iluminação foram completamente amortizados pelo aumento da produtividade dos funcionários em um único ano após a implantação do sistema (LightingControls, 2010).

Algumas estratégias tecnológicas quando aplicadas a estes sistemas podem maximizar sua viabilidade, como a utilização de lâmpadas com alta eficiência luminosa; uso de sensor de movimento; utilização de sensores de luminosidade, de maneira a adequar a iluminação local conjuntamente com o aproveitamento de luz natural; implementação de um sistema de gerenciamento remoto para acionamentos de acordo com a grade horária do expediente de trabalho, atuando de forma automática ou de acordo com preferências ou necessidades dos ocupantes do ambiente.

Uma das partes essenciais de um sistema de iluminação fluorescente é o reator que alimenta a lâmpada. Este elemento é indispensável para o correto funcionamento da mesma, isto devido à característica de resistência negativa que esta apresenta. Dentre os reatores, o reator eletrônico é o mais comumente utilizado. Os reatores eletrônicos convencionais possuem um estágio de entrada retificador com filtro capacitivo, apresentando elevada distorção harmônica para a corrente drenada da rede de corrente alternada (CA) e reduzido fator de potência (FP), tipicamente inferior a 0,6 . Neste contexto, por se tratar de uma carga considerável para os sistemas de distribuição em CA, técnicas especiais de correção do fator de potência devem ser aplicadas, para o atendimento integral às normas internacionais como a IEC 61000-3-2 (Alves et al., 1996; Co et al., 1998; Spangler et al., 1991; Tao et al., 2001; Lin and Chen, 2001).

Diversas pesquisas propõem técnicas de integração dos estágios retificador e inversor para a minimização do custo da implantação de um sistema de iluminação (Co et al., 1998; Tao et al., 2001; Lin and Chen, 2001). Outra maneira de se diminuir os custos é a adoção da configuração para múltiplas lâmpadas fluorescentes (Dalla Costa et al., 2002; Wakabayashi and Canesin, 2002; Walabayashi et al., 2004). Desse modo, um único estágio retificador com correção ativa do fator de potência e um único inversor são utilizados, sendo conectados a vários filtros ressonantes. No entanto, considerando-se uma área extensa a ser iluminada deve-se atentar aos prováveis problemas de interferências eletromagnéticas, uma vez que correntes de elevadas freqüências fluirão entre a saída do inversor e a entrada de cada filtro ressonante (Dalla Costa et al., 2002; Wakabayashi and Canesin, 2002; Walabayashi et al., 2004). A fim de evitar tais problemas utilizam-se projetos especiais de cabeamento estruturado, o que encarece sobremaneira a estrutura do sistema de iluminação. Adicionalmente, não é possível nestas estruturas o controle indi- vidual das lâmpadas ou de conjuntos setorizados devido a utilização de um único inversor, restringindo a funcionalidade do sistema no que tange às necessidades especiais dos ambientes e dos usuários do sistema.

Desta forma, este artigo apresenta um sistema de iluminação fluorescente multi-lâmpadas, com correção ativa do fator de potência de entrada, utilizando um estágio Pré- Regulador Retificador Boost controlado por um dispositivo FPGA, empregando a técnica dos valores médios instantâneos da corrente de entrada na forma digital (Brito et al., 2008). A transmissão de energia entre o capacitor de saída do retificador de entrada e cada reator eletrônico é realizado em corrente contínua, minimizando prováveis problemas de incompatibilidade eletromagnética. Isto é possível com o desenvolvimento de um filtro modificado inserido na entrada de cada estágio inversor.

O sistema de iluminação proposto apresenta reatores eletrônicos totalmente microcontrolados através de dispositivos Atmega8, e utilizando uma interface gráfica amigável, desenvolvida em Delphi 7.0, com um adequado protocolo de comunicação permite ao usuário e/ou microcomputador atuar de forma local e/ou remota alterando o ponto de operação de cada conjunto de reatores eletrônicos, de acordo com a necessidade dos usuários ou de acordo com agendamentos préestabelecidos; incorporando ainda sensores de iluminação e presença, de forma a otimizar o consumo de energia elétrica. Desta forma, o sistema constitui uma rede inteligente e eficiente (Smart Grid) para o controle e gerenciamento de um sistema de iluminação fluorescente (Contenti et al., 2007).

\section{SISTEMA MULTI-LÂMPADAS COM PRÉ-REGULADOR PARA CORREÇÃO DO FATOR DE POTÊNCIA}

Com o intuito de reduzir os problemas com interferências eletromagnéticas e custos associados com blindagem de cabos, o sistema proposto neste trabalho, conforme Figura 1, é composto por um único retificador controlado e vários estágios inversores, sendo estes alimentados em corrente contínua. A transmissão em corrente contínua é garantida com a inserção de um duplo filtro LC modificado. O estágio PréRegulador Retificador emprega a técnica dos valores médios instantâneos da corrente de entrada para a correção ativa do fator de potência, sendo controlado de forma digital por um dispositivo FPGA XC3S1000 Spartan 3.

O retificador controlado é responsável pelo fornecimento de energia a todos os estágios inversores, sendo que cada estágio inversor corresponde a um reator eletrônico para duas lâmpadas fluorescentes tubulares de 32 watts cada. Os estágios inversores devem ser posicionados o mais próximo possível das lâmpadas, para reduzir o comprimento dos cabos 


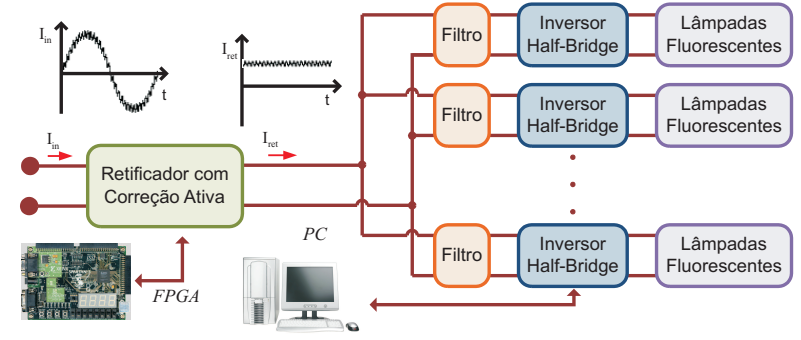

Figura 1: Concepção do sistema de iluminação multilâmpadas proposto.

que conduzem correntes em elevadas freqüências. Devido à essa configuração, é possível operar cada estágio inversor em diferentes freqüências, caso necessário, o que permite desenvolver luminosidade distinta para cada conjunto de lâmpadas. Quando aplicado em grandes ambientes ou em ambientes setorizados, esta característica torna o sistema ainda mais atrativo, já que cada local pode possuir uma incidência diferente de luz natural, com diferentes fluxos ou necessidades de usuários, otimizando o consumo de energia elétrica.

Conforme mencionado, um filtro de entrada conectado a cada estágio inversor é necessário. Com seu uso, eliminam-se os problemas relacionados com ressonâncias e circulação de correntes em elevadas freqüências pelo barramento de corrente contínua. Isto ocorre devido à característica ZVS (Zero Voltage Switching - entrada em condução com tensão nula) de funcionamento do estágio inversor. A estrutura desse filtro é apresentada na Figura 2. Vale destacar que o desenvolvimento desse filtro é uma inovação do projeto, não sendo observado em sistemas multi-lâmpadas convencionais.

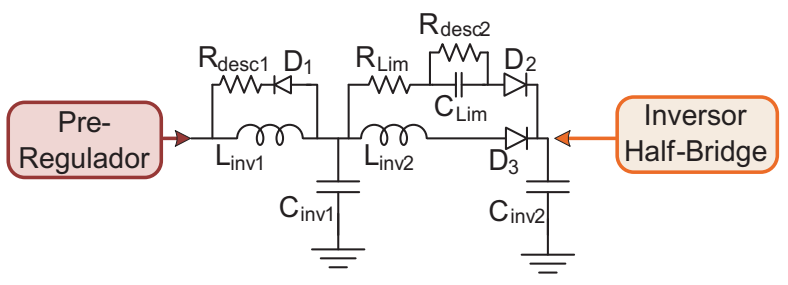

Figura 2: Circuito esquemático do filtro proposto.

Os estágios inversores são os clássicos meia ponte (Half Bridge) com filtro série-ressonante com carga em paralelo $(S P R L)$, os quais são amplamente utilizados em reatores eletrônicos convencionais (Cosby and Nelms, 1994). A Figura 3 representa o circuito esquemático do estágio inversor utilizado.

O projeto do filtro série-ressonante foi baseado na metodologia apresentada em (Wakabayashi and Canesin, 2005), utilizando-se do modelo da coluna de gás da lâmpada fluorescente empregado em (Wakabayashi, de Brito, Ferreira and Canesin, 2007).

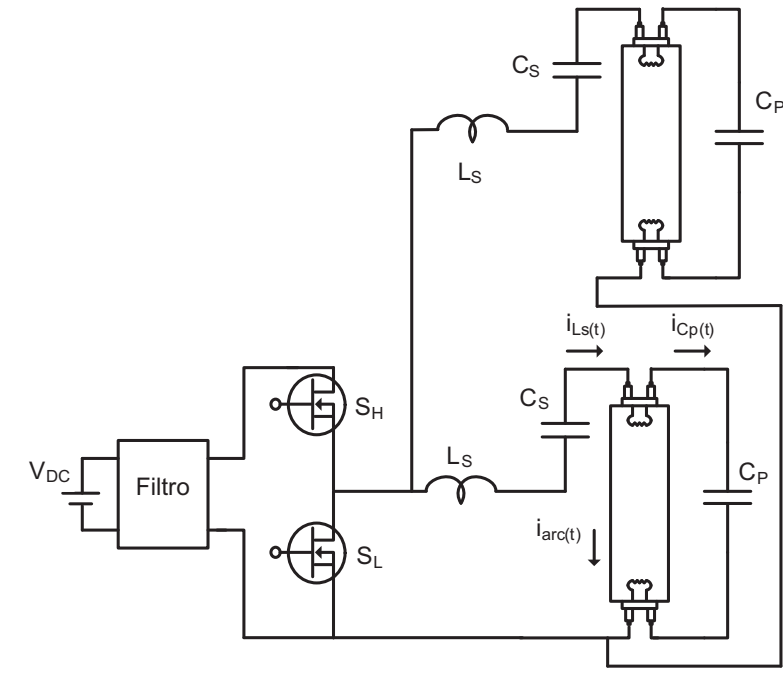

Figura 3: Circuito esquemático do estágio inversor Half Bridge com filtro SPRL.

Os dados básicos de projeto para o estágio inversor são a potência nominal na coluna de gás de $32 \mathrm{~W}$; potência mínima processada de $5 \mathrm{~W}$; tensão de alimentação de $400 \mathrm{~V}$; freqüência de comutação do estágio inversor em regime permanente na potência nominal de $50 \mathrm{kHz}$.

A partir destes dados, foram obtidos os seguintes parâmetros:

$\mathrm{L}_{s}=2,1 \mathrm{mH}, \mathrm{C}_{s}=180 \mathrm{nF}$ e $\mathrm{C}_{p}=8,2 \mathrm{nF}$.

Por se tratar de um estágio inversor Half Bridge com filtro $S P R L$, é possível impor o valor de corrente pela frequiência de comutação dos interruptores controlados. Assim, pode-se utilizar um protocolo de partida com uma etapa de pré-aquecimento adequado dos filamentos dos eletrodos por imposição de valor eficaz constante de corrente, adequando-se a freqüência de comutação e o tempo de pré-aquecimento de acordo com a metodologia de projeto proposta em (Wakabayashi, de Brito, Ferreira and Canesin, 2007). Isto reduzirá os desgastes dos filamentos dos eletrodos provocados durante a ignição das lâmpadas, promovendo uma maior vida útil para o sistema de iluminação (Wakabayashi, de Brito, Ferreira and Canesin, 2007). A faixa de valores eficazes de tensão nos filamentos dos eletrodos na potência nominal da lâmpada devem estar em conformidade com as normas ANSI (ANSI, 1993), situando-se entre 2,5V a 4,9V RMS.

A ignição das lâmpadas deve ocorrer com os filamentos aquecidos à temperaturas entre $700^{\circ} \mathrm{C}$ e $1000^{\circ} \mathrm{C}$ antes que haja o estabelecimento do primeiro arco através da coluna de gás. Para temperaturas abaixo de $700^{\circ} \mathrm{C}$, um fenômeno denominado de sputtering é aumentado, o qual acelera a taxa de perda da cobertura emissiva dos eletrodos. A par- 
tir de $1000^{\circ} \mathrm{C}$, a taxa de perda também se eleva, uma vez que ocorre evaporação excessiva da cobertura emissiva.

Realizar a medição da temperatura do filamento dos eletrodos não é simples, mas é interessante notar que a resistência equivalente dos eletrodos tem uma dependência direta com sua temperatura (Hammer and Haas, 1997; Ji et al., 1999). Desta forma, é possível assumir que a resistência equivalente pode ser usada para uma avaliação indireta deste parâmetro. De fato, diversos artigos recomendam a medição das resistências equivalentes como um sólido e confiável meio para investigar o processo de ignição (Hammer and Haas, 1997; Ji et al., 1999; Taylor, 2000). Na verdade, a recomendação geral é relacionada com a razão entre a "Resistência à Quente" $\left(\mathrm{R}_{h}\right.$, medida instantes antes da partida, usando um sistema de aquisição de dados) e a "Resistência à Frio" $\left(\mathrm{R}_{c}\right.$, medida com a lâmpada fora de operação durante pelo menos 5 minutos, usando um ohmímetro de precisão). O tempo de 5 minutos é necessário para que haja o completo resfriamento dos eletrodos. De acordo com a literatura, a razão $\mathbf{R}_{h} / \mathbf{R}_{c}\left(\mathbf{R}_{h c}\right)$ tem que ser maior do que 4,25 (aproximadamente $700^{\circ} \mathrm{C}$ ) e menor do que 6,25 (aproximadamente $1000^{\circ} \mathrm{C}$ ).

As normas ANSI estabelecem um intervalo de tempo mínimo $\left(\mathrm{t}_{p h}\right)$ de $500 \mathrm{~ms}$ para o desenvolvimento do processo de pré-aquecimento (ANSI, 1993). Além disso, apesar da ausência de um limite máximo para este intervalo de tempo, recomenda-se ajustar este limite em torno de 1,5 segundos, com o objetivo de evitar demora "excessiva" na ignição da lâmpada, o que causaria a falsa impressão de funcionamento indevido do sistema no ato de seu acionamento. A partir das recomendações para $\mathbf{R}_{h c}$ e $t_{p h}$, é possível identificar uma área de operação para o processo de pré-aquecimento, apresentado através da Figura 4. De posse do modelo proposto por Wakabayashi, Ferreira, de Brito and Canesin (2007), é possível saber a priori qual o valor eficaz (RMS) de corrente que deve ser injetado nos filamentos para maximização da vida útil do conjunto de lâmpadas. De posse do modelo e da área de operação, verifica- e que os valores RMS de corrente devem se situar entre $476 \mathrm{~mA}$ e $710 \mathrm{~mA}$, para o caso da lâmpada utilizada.

Uma análise interessante é que, de posse de um tempo previamente estabelecido é possível verificar o intervalo de corrente RMS mínima e máxima para garantir a grandeza $\mathbf{R}_{h c}$, ou mesmo, de posse de um valor RMS de corrente é possível verificar o intervalo de tempo mínimo e máximo para prover pré-aquecimento adequado; sendo estes observados na Figura 5.

Para a variação da potência processada na coluna de gás da lâmpada fluorescente, adota-se a técnica de variação da frequiência de comutação do estágio inversor, o que provoca alteração da característica da impedância do circuito, pro-

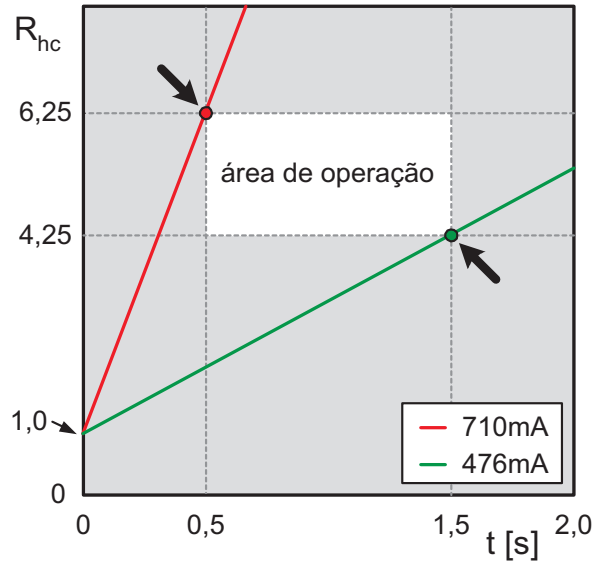

Figura 4: Área de operação para prover pré-aquecimento adequado dos filamentos dos eletrodos, considerando a lâmpada adotada.

movendo uma reconfiguração dos níveis de energia ativa e reativa processados (Wakabayashi and Canesin, 2005).

\section{SISTEMAS DE CONTROLE E GERENCI- AMENTO}

\subsection{Retificador de Entrada}

O estágio de entrada é composto pelo Pré-Regulador Retificador Boost, controlado pela técnica dos valores médios instantâneos da corrente de entrada, possuindo duas malhas de controle interdependentes. Uma malha de controle de corrente rápida que é responsável por garantir o formato senoidal retificado à corrente no indutor. Este formato é obtido através de uma tabela de valores internos, de amplitude unitária e sincronizada com a rede de alimentação. A outra malha de controle é a malha de realimentação da tensão de saída, que modifica a amplitude da corrente de referência de forma a garantir tensão de saída regulada e estabilizada. Malha esta de caráter lento a fim de não influenciar nas dinâmicas da malha de corrente, onde se optou por controlar o valor médio da tensão de saída ao invés de seu valor instantâneo, utilizando para tanto um filtro Notch digital sintonizado em $120 \mathrm{~Hz}$. Com a adoção de uma tabela de valores internos e o uso do filtro Notch minimizam-se possíveis distorções na corrente de referência. Esta técnica apresenta vantagens em relação ao controle analógico convencional, que faz a leitura instantânea da tensão de entrada e da tensão de saída, incorporando as distorções destas leituras na corrente de referência (Brito et al., 2008). O Diagrama esquemático simplificado do controle por valores médios na forma digital aplicado ao Pré-Regulador Retificador Boost está representado na Figura 6, onde $\mathrm{L}_{B}$ representa o indutor boost, $\mathrm{C}_{f} \mathrm{o}$ capacitor de saída e $\mathrm{R}_{L}$ a resistência de carga. 


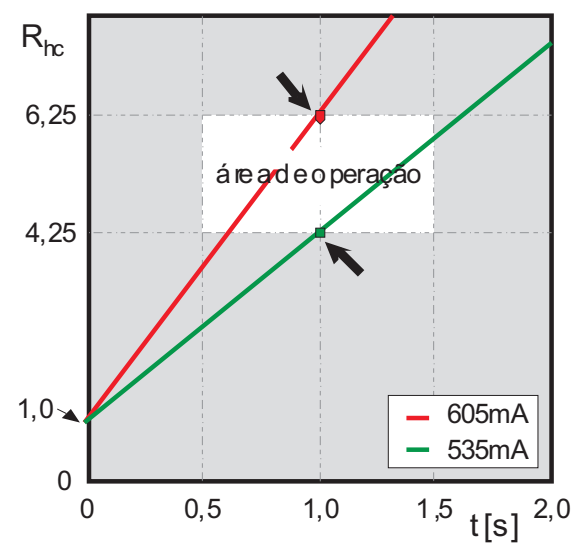

(a)

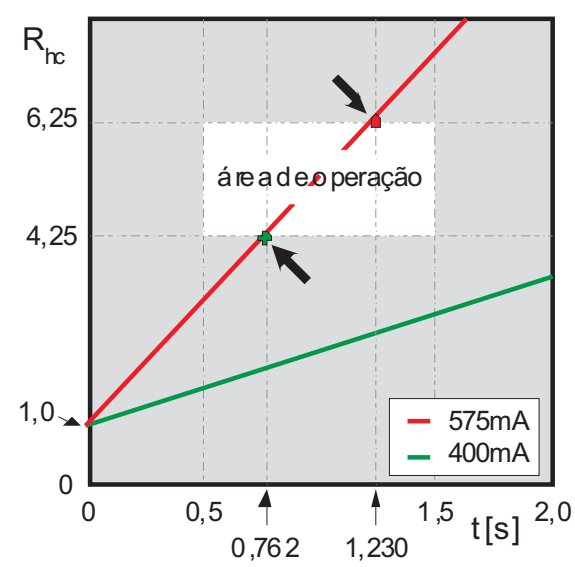

(b)

Figura 5: Análise da área de operação. (a) Variação de corrente RMS, considerando um dado intervalo de tempo para completar o pré-aquecimento. (b) Intervalo de tempo considerando a injeção de corrente com valor de 575mA RMS.

A malha de controle de corrente está representada na Figura 7 , e engloba o ganho do sensor de corrente $\left(\mathrm{K}_{i}\right)$, o filtro anti-aliasing (PB), o ganho do conversor $\mathrm{AD}\left(\mathrm{G}_{A D}\right)$, o compensador de corrente $\left(\mathrm{C}_{i}(\mathrm{z})\right)$, o ganho do modulador $\left(1 / \mathrm{K}_{P W M}\right)$ e a planta de corrente do conversor (Gid), juntamente com o retentor de ordem zero $(\mathrm{ZOH})$.

A malha de controle de tensão, representada na Figura 8, contempla o ganho do sensor de tensão $\left(\mathrm{K}_{v}\right)$, o filtro antialiasing, o ganho do conversor AD, o compensador de tensão $\left(C_{v}(z)\right)$, o multiplicador, a malha interna de corrente e a planta de tensão do conversor (Gvi).

As funções de transferência para o adequado projeto dos controladores do Pré-Regulador Retificador Boost foram obtidas usando a modelação por equações de estados média, escolhendo como variáveis de estado a corrente no indutor boost

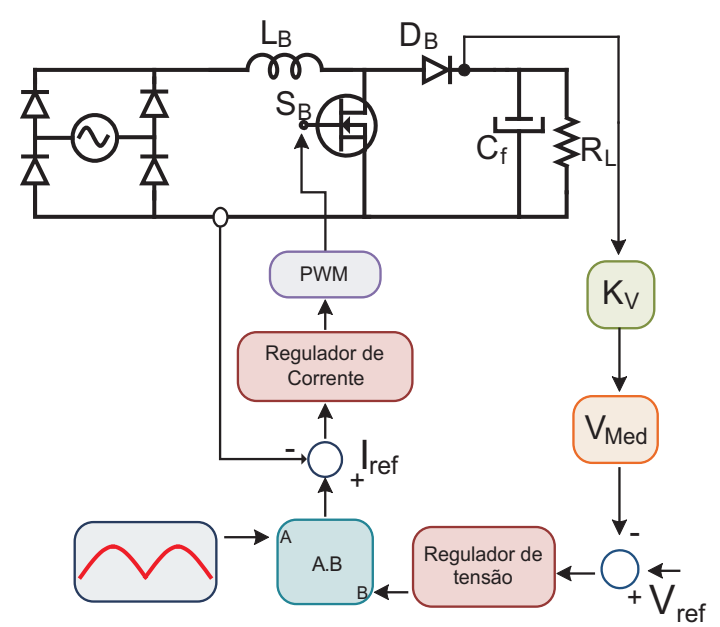

Figura 6: Diagrama esquemático simplificado do controle por valores médios na forma digital aplicado ao Pré-Regulador Retificador Boost.

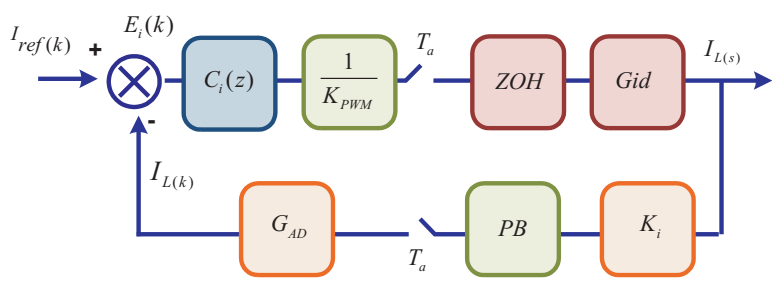

Figura 7: Malha de controle de corrente.

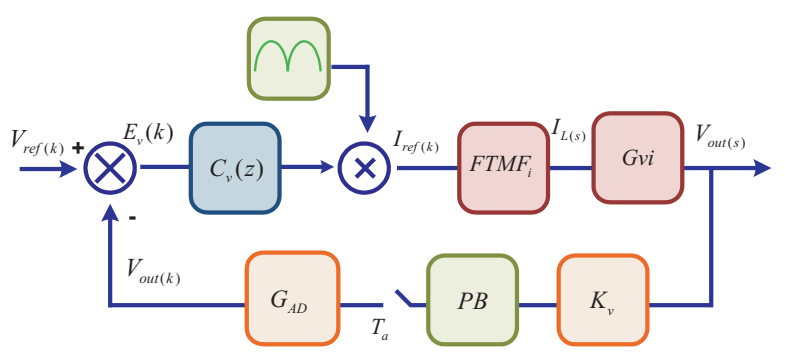

Figura 8: Malha de controle de tensão.

$\left(\mathrm{I}_{i}\right)$ e a tensão no capacitor de saída $\left(\mathrm{V}_{o}\right)$. A matriz de espaço de estados média foi obtida a partir da ponderação das matrizes de espaço de estados para cada etapa de funcionamento, utilizando- se como peso a razão cíclica (d).

A matriz de espaço de estados média é apresentada em (1).

$$
\begin{aligned}
{\left[\begin{array}{c}
\dot{V}_{o} \\
\dot{I}_{i}
\end{array}\right] } & =\left[\begin{array}{cc}
0 & \frac{(1-d)}{C} \\
-\frac{(1-d)}{L} & 0
\end{array}\right]\left[\begin{array}{c}
V_{o} \\
I_{i}
\end{array}\right]+ \\
& +\left[\begin{array}{cc}
0 & -\frac{1}{C} \\
\frac{1}{L} & 0
\end{array}\right]\left[\begin{array}{c}
V_{i} \\
\frac{V_{o}}{R_{L}}
\end{array}\right]
\end{aligned}
$$


Considerando o efeito da variável de controle d, as equações de espaço de estados médias são descritas conforme (2), também em função da tensão de entrada (Vin).

$$
\dot{x}=F\left(x, V_{i n}, d\right)
$$

Assim, o modelo a pequenos sinais se resume a (3)

$$
\begin{aligned}
\hat{\dot{x}} & =A^{\prime} \hat{x}+B^{\prime} \hat{v}_{i n}+K \hat{d} \\
A^{\prime} & =\frac{\partial F}{\partial x}, B^{\prime}=\frac{\partial F}{\partial v_{i n}}, K=\frac{\partial F}{\partial d}
\end{aligned}
$$

Aplicando as devidas transformadas de Laplace, considerando variações a pequenos sinais nulas na tensão de entrada, a função de transferência da variável de controle em função da razão cíclica é expressa por (4) (Erickson and Maksimović, 2001).

$$
\frac{\hat{x}}{\hat{d}}=\left(s I-A^{\prime}\right)^{-1} K
$$

Desta forma, são obtidas as funções de transferência $\mathrm{G}_{i d}(\mathrm{~s}) \mathrm{e}$ $\mathrm{G}_{v i}(\mathrm{~s})$. A função $\mathrm{G}_{i d}(\mathrm{~s})$ representa as variações de pequenos sinais na corrente do indutor quando da presença de variações de pequenos sinais na razão cíclica. Já a função de transferência $\mathrm{G}_{v i}(\mathrm{~s})$ representa as variações de pequenos sinais na tensão de saída pelas variações de pequenos sinais na corrente do indutor. Estas funções estão representadas em (5) e (6), respectivamente.

$$
G_{i d}(s)=\frac{2 V_{\text {out }}}{R_{L}(1-D)^{2}}\left[\frac{1+s C_{f}\left(\frac{R_{L}}{2}\right)}{1+s\left[\frac{L_{B}}{R_{L}(1-D)^{2}}\right]+s^{2} \frac{L_{B} C_{f}}{(1-D)^{2}}}\right]
$$

$$
G_{v i}(s)=(1-D) R_{L}\left[\frac{1}{1+s C_{f} R_{L}}\right]
$$

O projeto dos compensadores, tanto da malha de controle de tensão quanto da malha de controle de corrente, foi realizado diretamente no plano discreto, usando a ferramenta no domínio da freqüência, lançando mão dos diagramas de bode de módulo e de fase e considerando- se a aplicação da transformada w (Ogata, 1998). A vantagem do uso da transformada w é que se eliminam os problemas apresentados pelas técnicas de aproximação e se minimizam as taxas de amostragem necessárias, otimizando-se o projeto dos controladores digitais. Este método apresenta indices de desempenho maior do que o método de aproximação por emulação, uma vez que a transformada w é aplicada diretamente na função de transferência da planta discretizada. Como este método envolve as dinâmicas dos conversores $\mathrm{AD}$ e DA, tempos de amostragem relativamente maiores podem ser aplicados sem prejuízos para o desempenho do sistema.

Os compensadores escolhidos para as malhas de controle de corrente e de tensão são compensadores PI.

Para a malha de controle de corrente apresentam-se os diagramas de bode do sistema compensado, módulo e fase, Figuras 9 e 10, respectivamente. O sistema apresenta frequiência de cruzamento de ganho em torno de $5 \mathrm{kHz}$ e margem de fase de $56^{\circ}$, o que torna o sistema rápido e estável. As frequências de amostragem adotadas para adquirir a corrente no indutor e a tensão de saída são de $50 \mathrm{kHz}$ e $10 \mathrm{kHz}$, respectivamente. O compensador obtido para esta malha está apresentado em (7) e sua respectiva equação à diferenças, obtida via anti-transformada está apresentada em (8).

$$
P I_{\text {corrente }}(w)=1,445 \frac{(w+3142,6)}{w}
$$

$$
y(k)=y(k-1)+1,49 u(k)-1,40 u(k-1)
$$

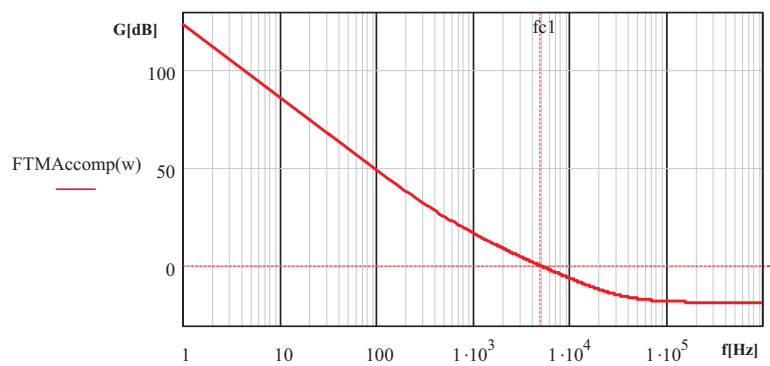

Figura 9: Diagrama de bode do módulo do sistema compensado no plano w, malha de corrente.

Para a malha de controle de tensão, são apresentados os diagramas de bode de módulo e de fase do sistema compensado, Figuras 11 e 12, respectivamente. O sistema compensado apresenta freqüência de cruzamento em $10 \mathrm{~Hz}$ e margem de fase de $94^{\circ}$, o que torna o sistema lento e estável. Assim, garante-se que a malha de tensão não influenciará nas dinâmicas da malha de corrente, garantindo que a forma de onda da corrente drenada da rede em CA apresente reduzido conteúdo harmônico e como consequência alto fator de potência. O compensador obtido no plano w é apresentado em 


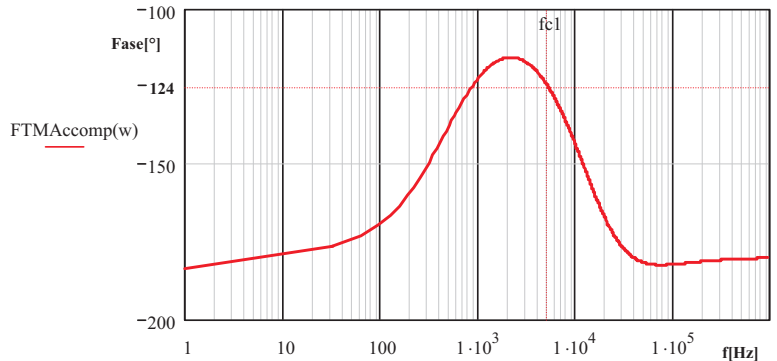

Figura 10: Diagrama de bode da fase do sistema compensado no plano w, malha de corrente.

(9) e a correspondente equação à diferenças, obtida via antitransformada, está representada em (10).

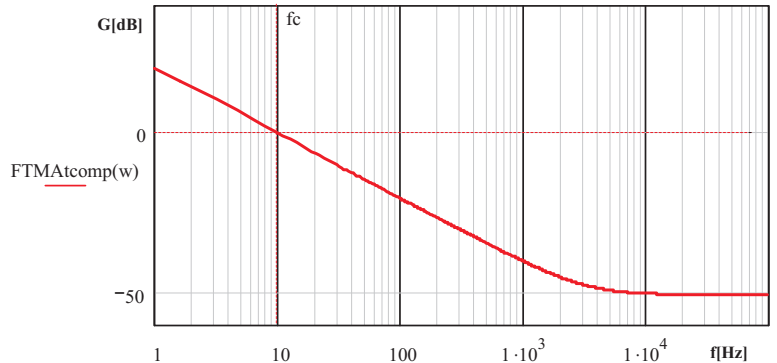

Figura 11: Diagrama de bode do módulo do sistema compensado no plano w, malha de tensão.

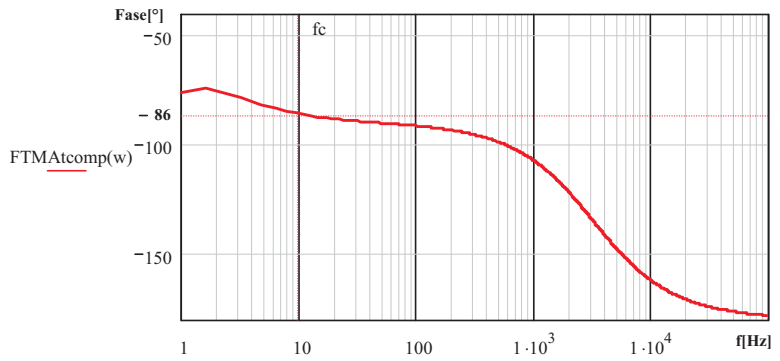

Figura 12: Diagrama de bode da fase do sistema compensado no plano w, malha de tensão.

$$
\begin{gathered}
P I_{\text {tensão }}(w)=6,135 \frac{(w+6,283)}{w} \\
y(k)=y(k-1)+6,14(k)-6,143 u(k-1)
\end{gathered}
$$

\subsection{Lógica de Controle em VHDL para o Estágio Retificador Boost}

A lógica de controle para o estágio Pré-Regulador Retificador Boost foi construída utilizando-se da linguagem de descrição de hardware VHDL em conjunto com os núcleos parametrizáveis de registradores, somadores e multiplicadores da biblioteca SystemGenerator. Criou-se sub-blocos para realizar as aquisições da corrente no indutor, da tensão de saída, para gerar a senóide interna e sincronizá-la com a rede, para geração dos pulsos PWM, partida suave e para as proteções. Estes sub-blocos foram interconectados através de uma entidade para compor toda a estratégia de controle, sendo esta apresentada na Figura 13. O FPGA utilizado foi um FPGA XC3S1000 Spartan 3, onde a lógica desenvolvida ocupou $23 \%$ da pastilha com um atraso máximo de propagação para os sinais de controle de 40,2 nanosegundos. Além disso, a frequiência máxima de operação do circuito digital de controle é de $23,4 \mathrm{MHz}$, sendo bem maior do que a máxima frequiência de aquisição, que é de $50 \mathrm{kHz}$. Fatos estes que demonstram a potencialidade da programação via FPGA.

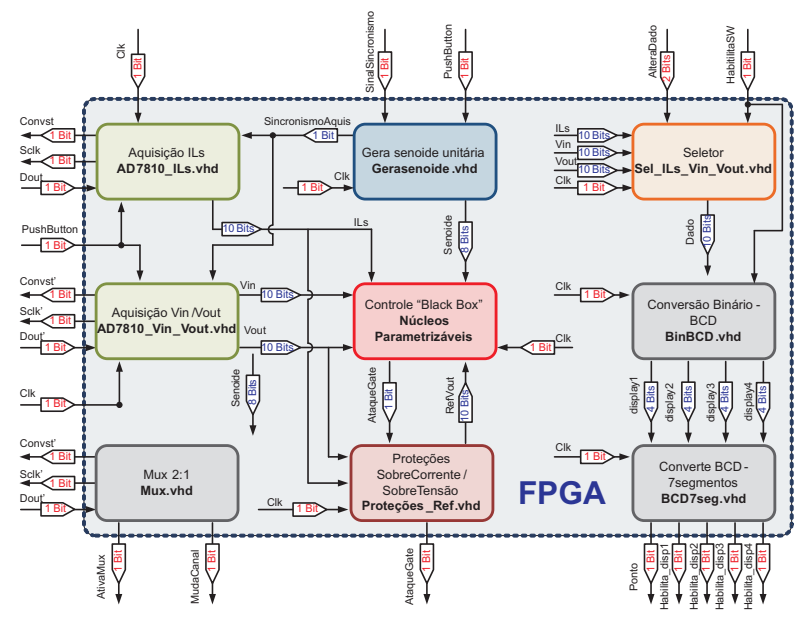

Figura 13: Diagrama de blocos geral do controle em FPGA.

Além disto, os filtros e compensadores foram implementados através da representação direta de sua equação à diferenças, usando aritmética de ponto fixo. Como exemplo de implementação de compensadores e de filtros, usando os núcleos paramatrizáveis, apresenta-se na Figura 14, o filtro Notch desenvolvido, que é um dos subcomponentes de um dos componentes da entidade.

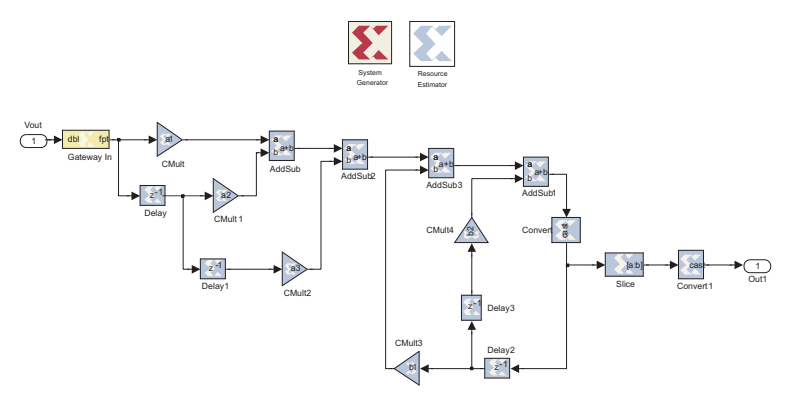

Figura 14: Filtro Notch implementado em FPGA.

Este filtro foi desenvolvido diretamente no plano discreto usando a ferramenta de projeto de filtros digitais FDAtool, 
presente no ambiente MatLab/Simulink. A freqüência deste filtro é de $120 \mathrm{~Hz}$ com a taxa de amostragem configurada como sendo $10 \mathrm{kHz}$. Para a realização deste filtro foram utilizados 5 multiplicadores, 4 somadores, 3 registradores e 3 estruturas de conversão de dados. As estruturas de conversão de dados são importantes para que o laço de realimentação não cause a instabilidade do filtro. A tabela 1 mostra os coeficientes do filtro e a sua configuração aritmética em ponto fixo.

Tabela 1: Configuração do filtro Notch digital.

\begin{tabular}{|c|c|c|c|}
\hline Coeficientes & Valor & $\mathrm{N}^{\circ}$ Bits & $\begin{array}{c}\text { Pos. Ponto } \\
\text { Fracionário }\end{array}$ \\
\hline $\mathbf{a 1}$ & 0,98426052692957455 & 18 & 18 \\
\hline $\mathbf{a 2}$ & $-1,9629282891983166$ & 20 & 18 \\
\hline $\mathbf{a 3}$ & 0,98426052692957455 & 18 & 18 \\
\hline $\mathbf{b 1}$ & 1,9629282891983166 & 19 & 18 \\
\hline $\mathbf{b 2}$ & $-0,96852105385187315$ & 18 & 18 \\
\hline
\end{tabular}

\subsection{Controle do Reator Eletrônico Utili- zando o Microcontrolador Atmega8}

Foi utilizado o microcontrolador Atmega8, o qual possui algumas funcionalidades que o torna interessante para o uso no controle dos reatores eletrônicos. Este dispositivo permite que, após configurada uma de suas saídas PWM para a liberação dos pulsos, na freqüência desejada para os interruptores controlados do estágio inversor, o microcontrolador prossiga executando outras rotinas, operando com eventos concorrentes. Por possuir canais de saída com conversores $\mathrm{AD}$ internos, há a possibilidade da utilização de sensores de luminosidade, tornando possível adquirir a luminosidade do ambiente e adequar a potência processada pela lâmpada fluorescente. Outra ferramenta também muito importante presente neste dispositivo é o USART (Universal Synchronous/Asynchronous Receiver/Transmitter). Este componente interno permite converter um dado serial para paralelo ou vice-versa, o que torna possível a interpretação e o processamento do dado serial enviado pelo microcomputador.

O processo de controle para o sistema de gerenciamento automático opera no modo mestre-escravo, sendo o microcomputador responsável pelo envio de ordens ao microcontrolador, o qual executará as devidas ações a ele desempenhadas; como por exemplo, acionamentos, desligamentos, controle de luminosidade e leitura do sensor de luminosidade e presença. Foi programado um protocolo de partida com préaquecimento adequado dos eletrodos das lâmpadas fluorescentes, para reduzir os desgastes provocados durante a igni- ção destas, maximizando a vida útil do sistema de iluminação multi-lâmpadas (Wakabayashi and Canesin, 2005).

A Figura 15 ilustra a interação existente entre o sistema de gerenciamento automático e o microcontrolador.

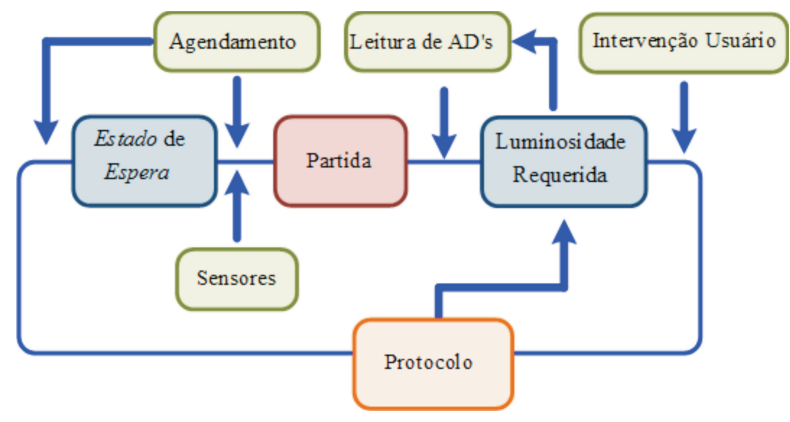

Figura 15: Diagrama de blocos representativo da atuação do sistema de gerenciamento.

\subsection{Interfaceamento e Protocolo de Co- municação entre Microcomputador e Microcontroladores}

Um protocolo de comunicação utilizando o canal full-duplex com transmissão de dados serial assíncrona de 8 bits (1byte), com transmissão de dados de 2.400 bits por segundo e com um único bit de parada (stop bit) e sem paridade foi desenvolvido para realizar o interfaceamento entre o microcomputador e cada microcontrolador. O canal full-duplex permite que blocos de mensagens sejam trocados simultaneamente em ambas as direções (canal bidirecional); assim, o sistema pode estar recebendo dados de um determinado reator e enviando dados para outro reator eletrônico simultaneamente (Axelson, 1999).

Neste trabalho, a utilização do padrão RS485 juntamente com o RS232 deve-se à desvantagem do padrão RS232 de possuir limitação com relação a distância entre dispositivos e não possibilitar comunicação ponto a ponto. Utilizando o padrão RS485 é possível prover uma comunicação entre vários dispositivos sem se preocupar com a distância entre eles. A distância total de cabeamento apresenta limite de até $1200 \mathrm{~m}$ em baixas velocidades utilizando somente cabos não blindados. Estas vantagens apresentadas pelo padrão RS485 devem-se ao modo de operação diferencial, minimizando efeitos de terra flutuante. Para o interfaceamento destes padrões de comunicação foi utilizado o circuito integado (CI) MAX232, que converte de RS232 para TTL e, em seguida, de TTL para RS485 utilizando o CI SN75179. Em cada reator é convertido o sinal de RS485 para TTL, o qual é o padrão de comunicação dos microcontroladores. $\mathrm{O}$ interfaceamento do sistema completo pode ser visualizado nas Figuras 16 e 17. 
Microcomputador - PC

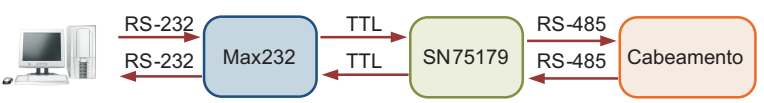

Figura 16: Interfaceamento do sistema até o cabeamento.

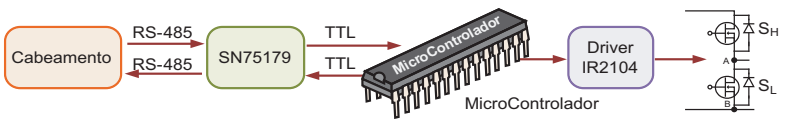

Figura 17: Interfaceamento do cabeamento até cada estágio inversor.

O protocolo de comunicação utilizado foi criado para fazer o endereçamento e o controle dos acionamentos realizados pelo aplicativo. Existem outros protocolos de comunicação vigentes e alguns até normatizados. Um protocolo exclusivo para o controle de sistemas de iluminação artificial normatizado é denominado DALI (Digital Addressable Lighting Interface), regido pela norma IEC 60929, o qual já está sendo adotado como padrão por grandes fabricantes de reatores eletrônicos, como a OSRAM, a Philips Lighting e a International Rectifier, por exemplo. No entanto, este protocolo permite acoplar ao sistema somente 64 dispositivos, com limite de velocidade de transferência de dados de 1.200 bits por segundo, além de utilizar cinco condutores para se comunicar (Contenti et al., 2007). A utilização de cinco condutores se deve a opção de bidirecionalidade na troca simultânea de informações e no envio do cabeamento de terra. Existe a alternativa de utilização do protocolo DALI em sua versão unidirecional (com direção revertida mas não simultânea) a dois fios (half-duplex) e sem sinal de terra para blindagem.

Com relação ao protocolo desenvolvido neste trabalho este possui vantagens de não limitar o número de dispositivos acoplados ao sistema, além de prover a comunicação utilizando somente três condutores, minimizando custos e problemas com interferências eletromagnéticas. Ademais, se adapta a qualquer taxa de transferência, possibilitando a expansão do protocolo para a utilização da porta $U S B$, a qual opera com elevadas taxas de transferências de dados, além de oferecer bidirecionalidade na troca de informações entre os diversos dispositivos.

Os dados de comunicação trafegados pelo canal de comunicação estão codificados em ASCII (American Standard Code for Information Interchange) e são interpretados pelo microcomputador e pelo microcontrolador. Cada ordem enviada pelo microcomputador ao microcontrolador possui 2 bytes: o primeiro é o endereçamento do reator eletrônico e o segundo é a ordem de mudança do estado. Caso o microcontrolador não possua o endereçamento correspondente ao dado, ele permanece no estado anterior à recepção do dado. Para a leitura do sensor de luminosidade, o microcomputador envia somente um byte designado pelo protocolo a cada intervalo de tempo definido e os microcontroladores executam a leitura dos conversores ADs para que seja readequado o nível de luminosidade, caso necessário, desde que o reator eletrônico não esteja sofrendo alguma intervenção do sistema de gerenciamento.

A interface gráfica e remota desenvolvida em Delphi 7.0 tem o intuito de promover uma interface homem-máquina amigável ao usuário, permitindo que qualquer usuário, mesmo leigo possa operar o sistema. Este aplicativo permite a intervenção ou monitoramento de cada reator, executar os acionamentos e/ou variar independentemente as luminosidades. A partir dele, pode-se ter acesso ao agendamento de acionamentos em função do dia da semana e do expediente de trabalho do ambiente, programando acionamentos e desligamentos de acordo com o horário e/ou necessidade.

Apesar de se ter vários dispositivos e muitas variáveis de controle, o software utiliza formulários-mestres, sendo a acumulação de dados interna realizada com a utilização de matrizes. Assim, simplificam-se as tarefas indexando-se linhas e colunas das matrizes para cada tarefa desejada.

\section{RESULTADOS EXPERIMENTAIS}

Os resultados apresentados correspondem a um conjunto de 15 reatores eletrônicos, com duas lâmpadas fluorescentes F32T8 (32W) para cada reator, totalizando 960 watts de potência luminosa. Na Figura 18 apresentam-se as formas de onda de tensão e de corrente na entrada do estágio PréRegulador Retificador Boost, para carga nominal, onde se verifica a excelente qualidade da forma de onda de corrente drenada do sistema de alimentação em CA, apresentando uma taxa de distorção harmônica de apenas 3,5\% e fator de potência FP de 0,997, com rendimento da estrutura em torno de $95 \%$.

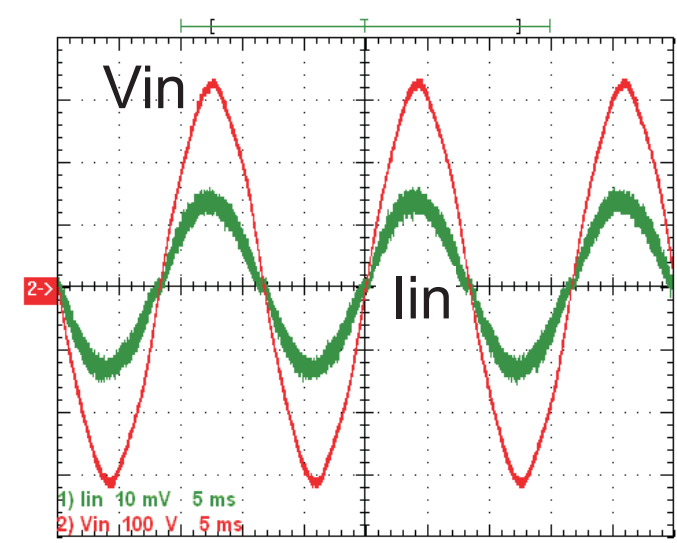

Figura 18: Formas de onda da corrente (lin) e da tensão (Vin) de entrada; (100V/div; 5A/div; 5ms/div). 
Para verificar a qualidade dos compensadores projetados, degraus de carga foram aplicados no sistema de iluminação, sendo estes de meia carga para carga nominal e vice-versa, onde na Figura 19 pode-se observar que a forma de onda de corrente de entrada sempre mantém o formato senoidal e se estabiliza no valor de regime em menos de 2 ciclos de rede.

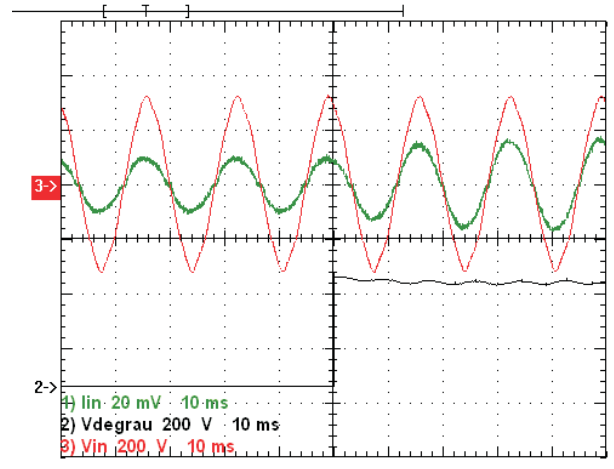

(a)

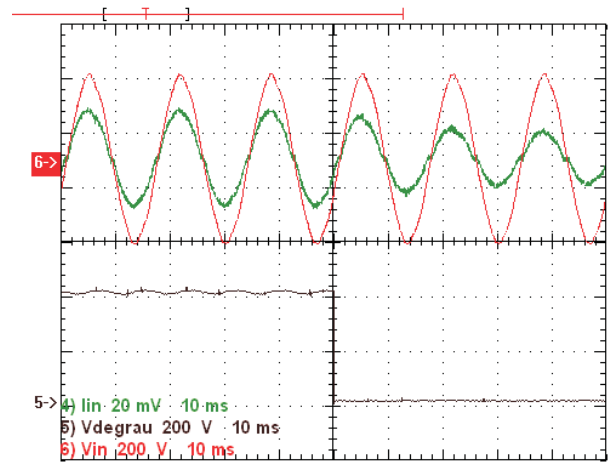

(b)

Figura 19: Degraus de carga aplicados. (a) Detalhe do degrau de meia carga para nominal; (b) Detalhe do degrau de carga nominal para meia carga. (200V/div; 10A/div; $10 \mathrm{~ms} / \mathrm{div})$.

Um protocolo de partida suave para o estágio Pré-Regulador foi desenvolvido a fim de que o mesmo apresentasse um comportamento adequado de inrush, seguindo como referência uma rampa de tensão pré-estabelecida. Na Figura 20 são apresentadas as formas de onda deste conversor durante a partida.

Na Figura 21 é apresentada a tela inicial do programa para intervenção no sistema de iluminação via microcomputador, onde o usuário do sistema pode optar pela utilização em modo "manual"ou "automático".

Durante a utilização em modo "manual"o usuário pode atuar em cada calha separadamente, de acordo com o formulário apresentado na Figura 22.

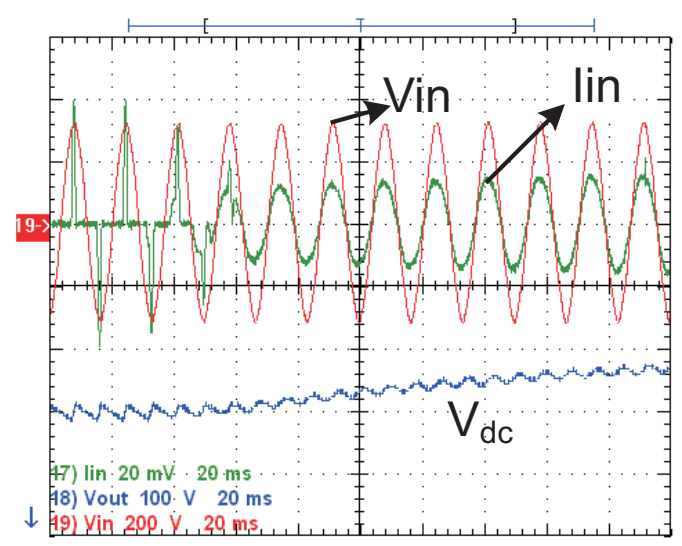

Figura 20: Formas de onda da corrente (lin), da tensão de entrada (Vin) e da tensão no barramento CC (Vdc) (100V/div; 10A/div; 20ms/div).

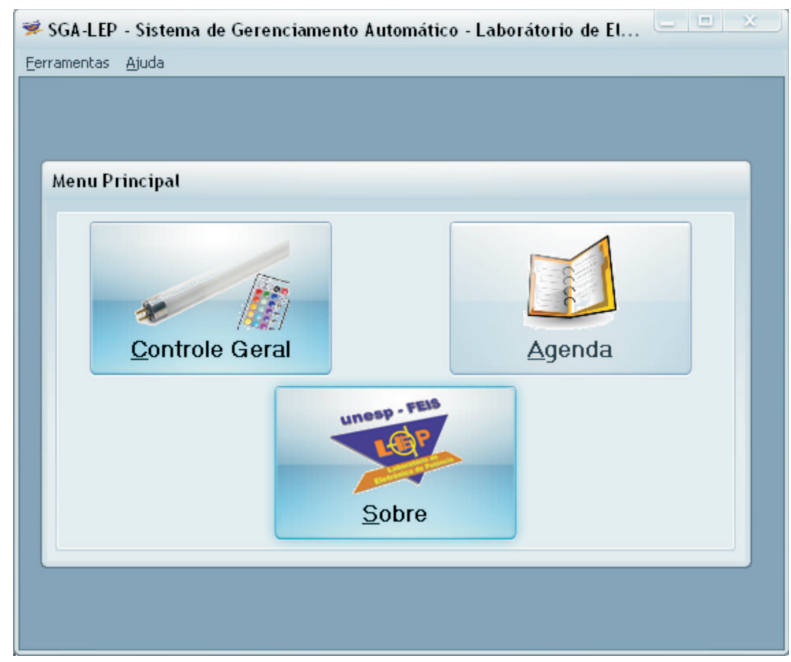

Figura 21: Formulário inicial que possibilita a alteração do modo de operação do sistema de iluminação.

Após a seleção da calha, um novo formulário é executado, conforme Figura 23, o qual permite que o usuário tenha acessos a acionamentos, monitoração da porcentagem da potência processada na lâmpada em relação à nominal, permitindo que que o usuário varie a luminosidade de cada conjunto de lâmpadas, além de permitir o acesso aos agendamentos de acionamentos em função do dia da semana e ajuste do nível de luminosidade pelo usuário, conforme mostra a Figura 24.

Durante o processo de partida cada reator eletrônico préaquece os filamentos dos eletrodos das lâmpadas fluorescentes, maximizando sua vida útil. $\mathrm{O}$ protocolo foi pré-programado utilizando-se da metodologia proposta em (Wakabayashi and Canesin, 2005). Para o processo de préaquecimento do conjunto de lâmpadas idênticas utilizadas, foi injetado um valor eficaz constante de corrente de $500 \mathrm{~mA}$ 


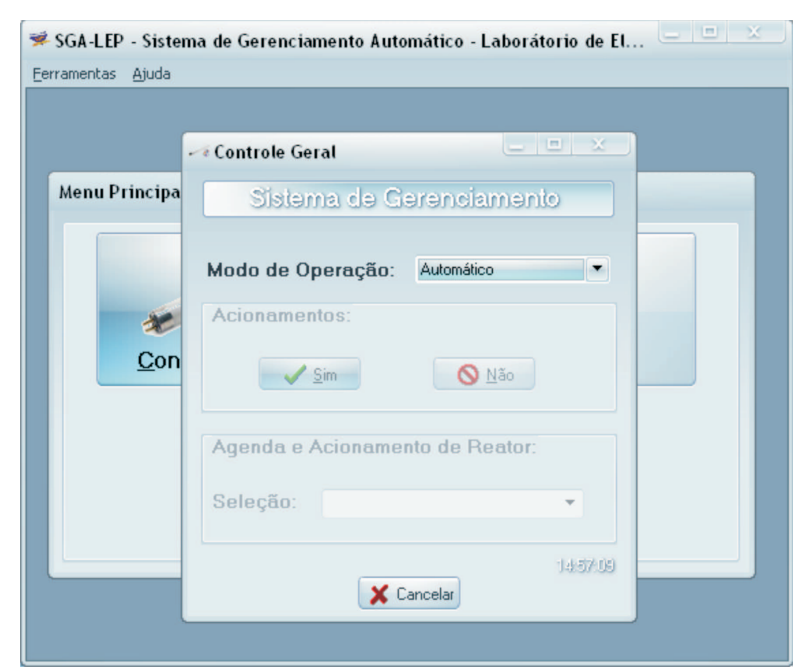

Figura 22: Seleção da calha onde o usuário pode atuar de forma remota.

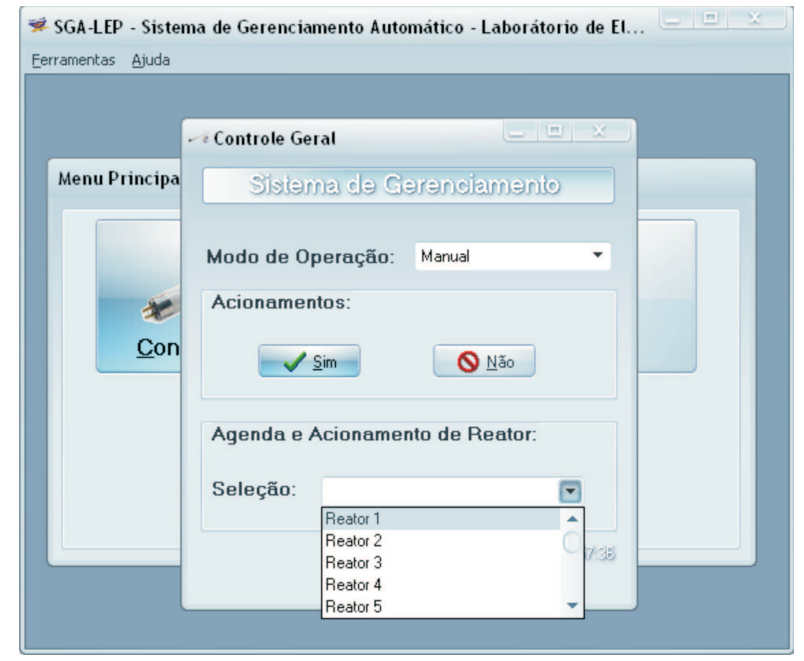

Figura 23: Acionamentos e Monitoramentos da "Calha 1".

nos filamentos dos eletrodos durante 1,42 segundos, como pode ser observado na Figura 25.

Com este protocolo de pré-aquecimento, o valor obtido para a grandeza $\mathrm{R}_{h c}$ foi de $5,02((20,86 \mathrm{~V} / 1,67 \mathrm{~A}) / 2,489 \Omega)$, garantindo a eficácia do processo de pré-aquecimento e ignição. Em regime permanente, a lâmpada fluorescente operará na sua potência nominal até que o microcomputador ordene que o microcontrolador faça a leitura do conversor $\mathrm{AD}$, onde está acoplado o sensor de luminosidade, habilitando a necessária alteração do nível de luminosidade, ou até que ocorra alguma intervenção pelo usuário no sistema de gerenciamento.

Observa-se que todas as lâmpadas são sempre acionadas para a condição nominal, permitindo-se o controle de luminosidade somente após a execução do protocolo completo de ignição. Adicionalmente, pode-se ainda ajustar o pro-

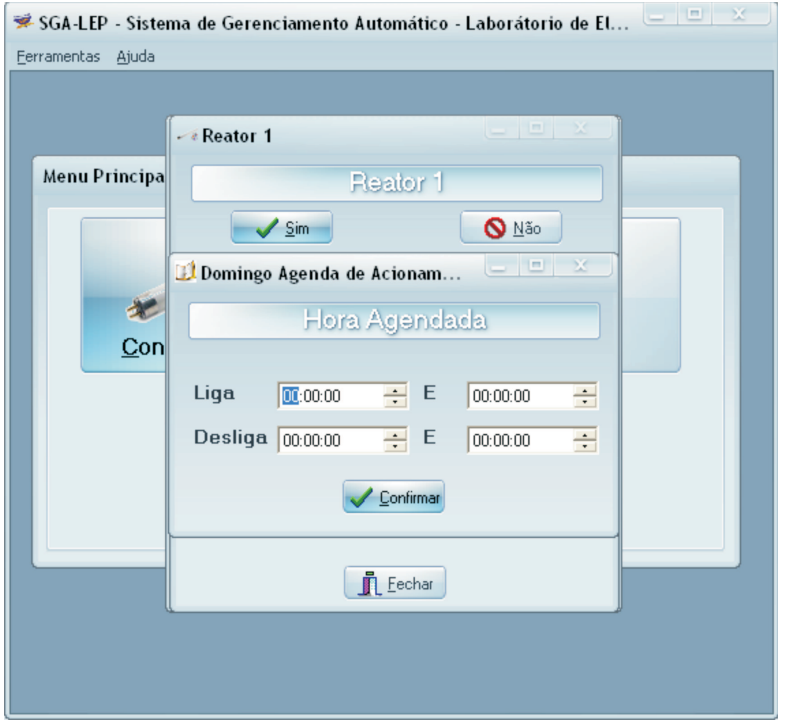

(a)

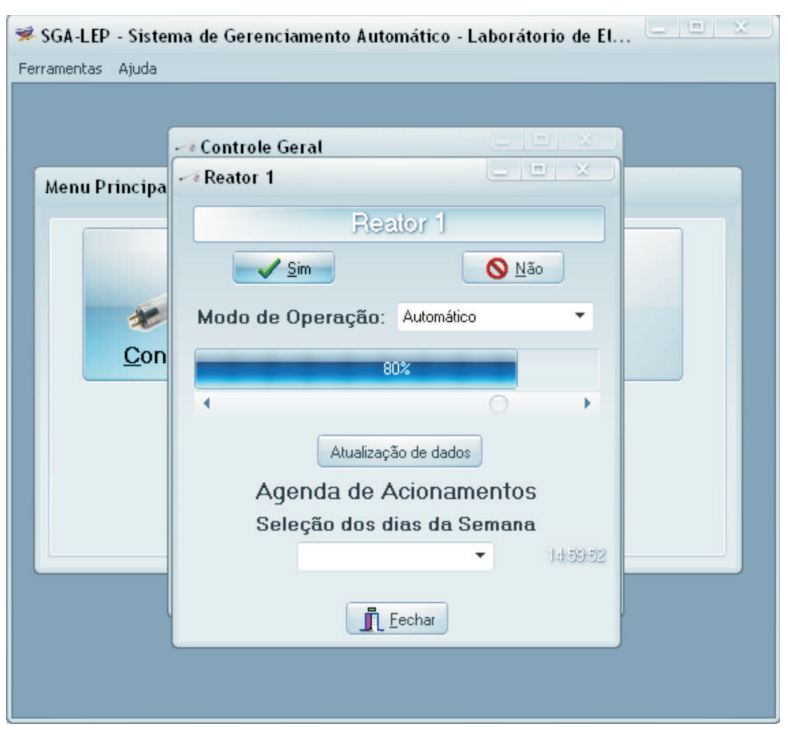

(b)

Figura 24: Acionamentos conforme: (a) dia da semana e (b) ajuste do nível de luminosidade pelo usuário.

tocolo de pré-aquecimento de acordo com a alteração do tipo/fabricante das lâmpadas.

A Figura 26 apresenta as formas de onda da tensão nos filamentos dos eletrodos, cujo valor eficaz está de acordo com as normas ANSI (4,29 V), a corrente de entrada do estágio inversor e a corrente de entrada do filtro do estágio inversor, quando um reator eletrônico opera na potência nominal e freqüência de comutação dos interruptores em $50 \mathrm{kHz}$. Na Figura 27 são apresentadas as formas de onda de corrente e de tensão na lâmpada para a potência nominal. 


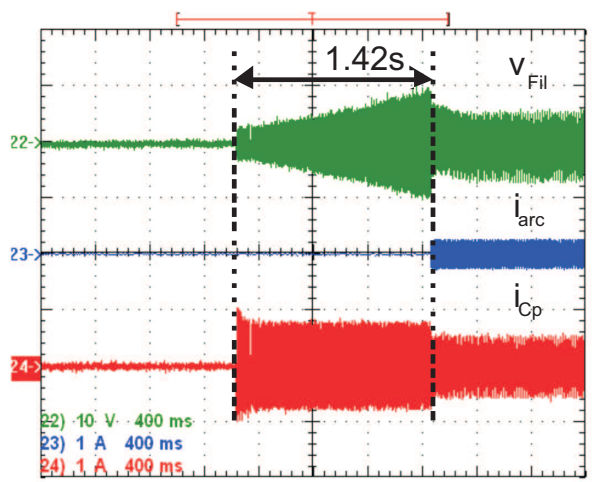

(a)

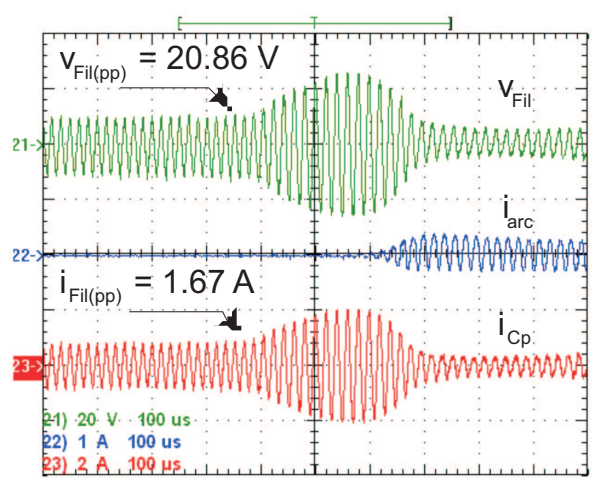

(b)

Figura 25: Tensão nos filamentos dos eletrodos $\left(\mathrm{V}_{F I L}\right)$, corrente na coluna de gás da lâmpada $\left(\mathrm{i}_{\text {arc }}\right.$ ) e corrente no capacitor $\mathrm{Cp}\left(\mathrm{i}_{C p}\right)$. (a) Duração do pré- aquecimento. (b) Instantes antes da ignição.

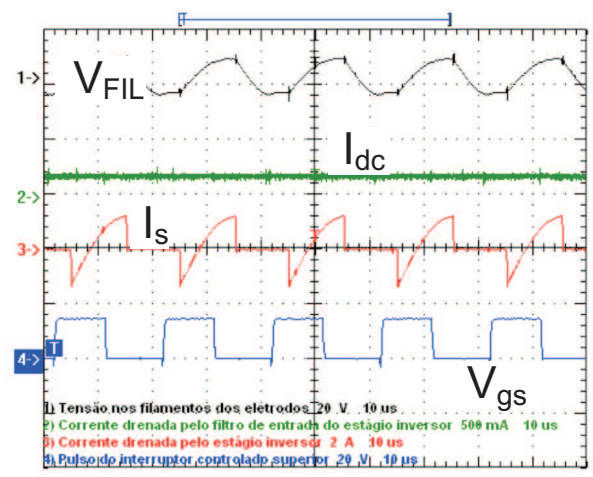

Figura 26: Tensão nos filamentos dos eletrodos $\left(\mathrm{V}_{F I L}\right)$; Corrente drenada pelo filtro de entrada do reator eletrônico (Idc); Corrente drenada pelo estágio inversor (Is); Pulso de acionamento do interruptor controlado superior/inversor (Vgs).

A partir da atuação do usuário no sistema de gerenciamento ou pelo nível de luminosidade ambiente sensorado, o reator passará a operar em outro ponto de operação, como por

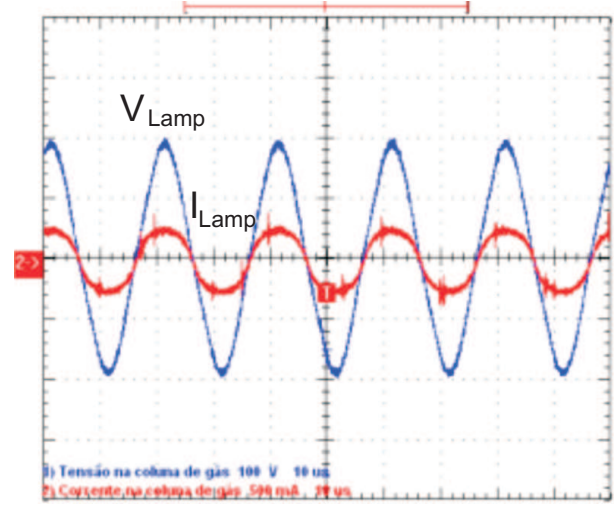

Figura 27: Formas de onda de tensão $\left(\mathrm{V}_{\text {Lamp }}\right)$ e de corrente $\left(I_{\text {Lamp }}\right)$ na coluna de gás com potência nominal em uma lâmpada. (100V/div, 500mA/div, 10us;div).

exemplo, a $50 \%$ da potência nominal. Assim, as Figuras 28 e 29 apresentam as formas de onda de um reator eletrônico para tal potência e frequiência de comutação dos interruptores em $53,20 \mathrm{kHz}$

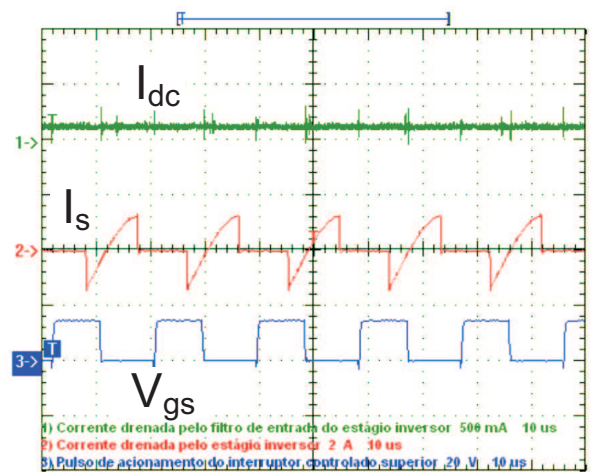

Figura 28: Corrente drenada pelo filtro de entrada do reator eletrônico (Idc); Corrente drenada pelo estágio inversor (Is); Pulso de acionamento do interruptor controlado superior/inversor (Vgs).

Com o intuito de se verificar a funcionalidade do duplo filtro LC modificado, foram feitas medições da corrente e da tensão em um dos interruptores do estágio inversor, da corrente drenada do conversor Boost pelo reator eletrônico e da tensão de barramento $\mathrm{CC}$ do conversor, sendo estas representadas nas Figuras 30(a) e 30(b), respectivamente. Com a adição deste filtro, verifica-se que são resolvidos os problemas de incompatibilidade eletromagnética.

\section{CONCLUSÕES}

Este artigo apresentou um sistema de iluminação fluorescente multi-lâmpadas possibilitando a redução das distorções harmônicas da corrente drenada do sistema de alimentação, utilizando o controle digital por valores médios da 


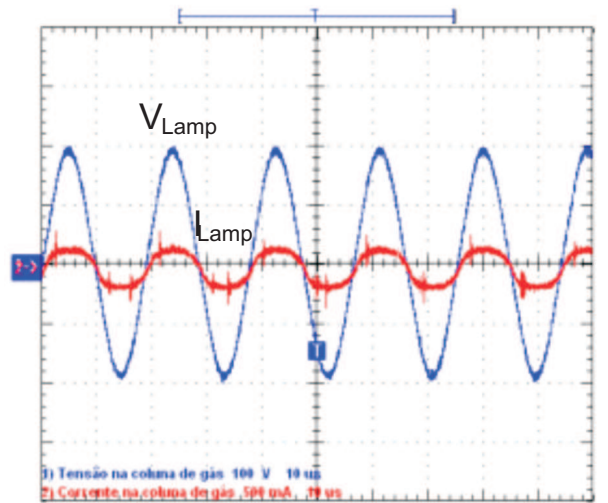

Figura 29: Formas de onda de tensão $\left(\mathrm{V}_{\text {Lamp }}\right)$ e de corrente $\left(\mathrm{I}_{\text {Lamp }}\right)$ na coluna de gás com metade da potência. (100V/div, $500 \mathrm{~mA} / \mathrm{div}, 10 \mathrm{us} / \mathrm{div})$.

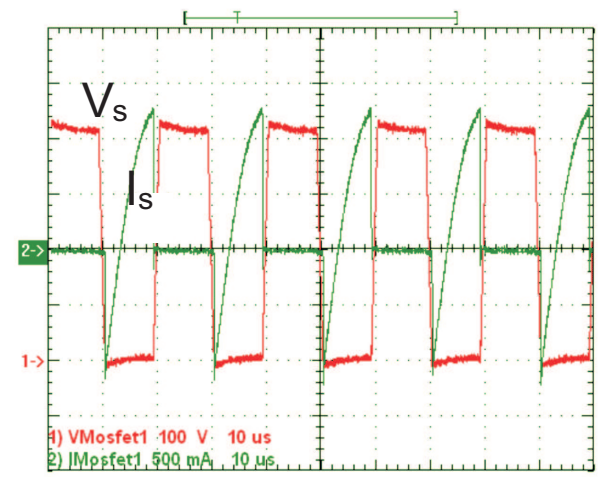

(a)

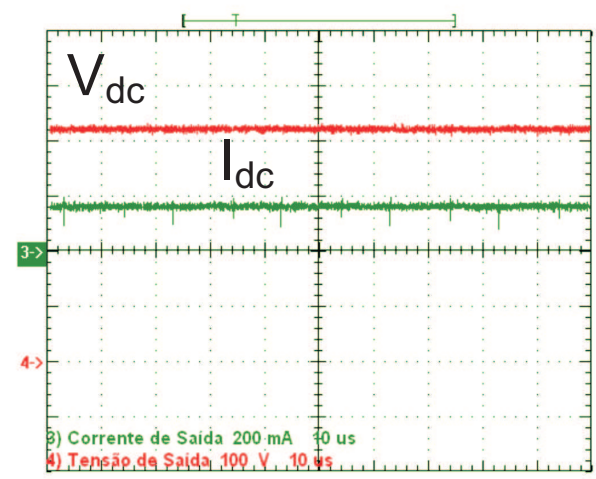

(b)

Figura 30: (a) Formas de onda de tensão (Vs) e corrente em um dos MOSFETS (Is) para a potência nominal em um reator. (b) Formas de onda da tensão de barramento CC $(\mathrm{Vdc})$ e da corrente drenada pelo reator (Idc).

corrente de entrada e sendo controlado por um dispositivo FPGA. Além disso, apresenta controle pré-programado do pré-aquecimento dos eletrodos, controle de luminosidade individual de cada conjunto de duas lâmpadas fluorescentes, monitoramento e gerenciamento remoto e sensores de luminosidade e de presença, permitindo assim um controle eficiente do sistema de iluminação, maior vida útil e otimização do consumo de energia elétrica. O sistema utiliza microcontroladores Atmega8 e um aplicativo em plataforma amigável ao usuário, onde é possível gerenciar e supervisionar o sistema de iluminação multi-lâmpadas fluorescentes, executar acionamentos remotos e agendamentos em função do expediente de trabalho do ambiente.

Com o auxílio de sensores de luminosidade é possível adaptar a luminosidade à necessidade do local, podendo haver pleno aproveitamento da luz natural, o que torna em algumas ocasiões a iluminação artificial complementar à natural, reduzindo o consumo de energia elétrica destinado à iluminação, podendo substituir os atuais sistemas de iluminação convencionais. Portanto, o sistema proposto se constitui como uma rede eficiente para o controle da iluminação fluorescente, podendo ainda evoluir com técnicas de inteligência artificial para a otimização do controle de luminosidade, da eficiência e do gerenciamento do sistema.

\section{AGRADECIMENTOS}

Os autores agradecem à FAPESP e ao CNPq pelo suporte financeiro concedido para o desenvolvimento deste trabalho.

\section{REFERÊNCIAS}

Alves, J., Perin, A. and Barbi, I. (1996). An electronic ballast with high power factor for compact fluorescent lamps, Conference Record of the 1996 IEEE Industry Applications Conference, 1996. Thirty-First IAS Annual Meeting, IAS '96., Vol. 4, pp. 2129-2135.

ANSI (1993). American Nacional Standart for Ballasts for Fluorescent Lamps - Specifications, ANSI C82.11985 and C82.11-1993.

Axelson, J. (1999). Serial Port Complete - Programming and Circuits for RS-232 and RS-485 Links and Networks, 1 edn, Lakeview Research, USA.

Brito, M. A. G., Ferreira, C. S. and Canesin, C. A. (2008). Pr?-regulador retificador boost com controle digital por valores m?dios, utilizando dispositivo fpga e vhdl, VII INDUSCON, 2008.

Co, M., Simonetti, S. and Vieira, J. (1998). High-powerfactor electronic ballast operating in critical conduction mode, IEEE Transactions on Power Electronics 13(1): 93-101.

Contenti, C., Ribarich, T. and Fosler, R. (2007). Digital dimming dali ballast for $32 \mathrm{w} / \mathrm{t} 8110 \mathrm{v}$ input. International Rectifier - Reference Design, pp 1-14. 
Cosby, M.C., J. and Nelms, R. (1994). A resonant inverter for electronic ballast applications, IEEE Transactions on Industrial Electronics 41(4): 418-425.

Dalla Costa, M. A., Landerdahl, M. L. and Prado, R. N. (2002). Independent multi-lamp electronic ballast, $I N$ DUSCON 2002.

Erickson, R. W. and Maksimović, D. (2001). Fundamentals of Power Electronics, 3 edn, Kluwer Academic Publisher, USA.

Hammer, E. and Haas, D. (1997). Photocell enhanced technique for measuring starting electrode temperatures of fluorescent lamps, Conference Record of the 1997 IEEE Industry Applications Conference, 1997. Thirty-Second IAS Annual Meeting, IAS '97., Vol. 3, pp. 2313-2333.

Ji, Y., Davis, R., O'Rourke, C. and Chui, E. (1999). Compatibility testing of fluorescent lamp and ballast systems, IEEE Transactions on Industry Applications 35(6): 1271-1276.

Lighting-Controls (2010). Energy design resources, Dispon?vel em www.energydesign-resources. com. Acesso em 05 de abril de 2010.

Lin, C.-S. and Chen, C.-L. (2001). A novel single-stage push-pull electronic ballast with high input power factor, IEEE Transactions on Industrial Electronics 48(4): 770-776.

MME (2007). Minist?rio de Minas e Energia - Plano Nacional de Energia 2030, Dispon?vel em www . mme. gov.br/mme/menu. Acesso em 19 de julho de 2010.

Ogata, K. (1998). Engenharia de Controle Moderno, 3 edn, LTC, Rio de Janeiro.

Spangler, J., Hussain, B. and Behera, A. (1991). Electronic fluorescent ballast using a power factor correction technique for loads greater than 300 watts, Sixth Annual Applied Power Electronics Conference and Exposition, 1991. APEC '91. Conference Proceedings, 1991., pp. 393-399.
Tao, F., Zhao, Q., Lee, F. and Onishi, N. (2001). Singlestage power-factor-correction electronic ballast with a wide continuous dimming control for fluorescent lamps, IEEE 32nd Annual Power Electronics Specialists Conference, 2001. PESC, 2001, Vol. 2, pp. 926931.

Taylor, A. (2000). Electronic ballasts, National Lighting Product Information Program 8(1): 1-32.

Wakabayashi, F. and Canesin, C. (2002). A high efficiency hpf-zcs-pwm sepic for electronic ballast with multiple tubular fluorescent lamps, Seventeenth Annual IEEE Applied Power Electronics Conference and Exposition, 2002. APEC 2002., Vol. 2, pp. 924-930.

Wakabayashi, F. and Canesin, C. (2005). An improved design procedure for lcc resonant filter of dimmable electronic ballasts for fluorescent lamps, based on lamp model, IEEE Transactions on Power Electronics 20(5): 1186-1196.

Wakabayashi, F., de Brito, M., Ferreira, C. and Canesin, C. (2007). Setting the preheating and steady-state operation of electronic ballasts, considering electrodes of hot-cathode fluorescent lamps, IEEE Transactions on Power Electronics 22(3): 899-911.

Wakabayashi, F., Ferreira, C., de Brito, M. and Canesin, C. (2007). Model for electrodes' filaments of hot cathode fluorescent lamps, during preheating with constant rms current, IEEE Transactions on Power Electronics 22(3): 719-726.

Walabayashi, F., de Oliveira, R. and Canesin, C. (2004). High power factor dimmable electronic ballast for multiple tubular fluorescent lamps, IEEE International Symposium on Industrial Electronics, 2004, Vol. 2, pp. 1063-1068. 